\title{
Supplementation of Carica papaya Leaves (Carica papaya L.) in Nori preparation Reduced Blood Pressure and Arterial Stiffness on Hypertensive Animal Model
}

\author{
Patonah Hasimun*, Agus Sulaeman, Intan Dwi Puspita Maharani \\ Faculty of Pharmacy, Bhakti Kencana University, Bandung, West Java, INDONESIA.
}

\begin{abstract}
Objectives: Hypertension is defined as an increase in systolic and/or diastolic blood pressure of more than 140/90 $\mathrm{mmHg}$. Epidemiological studies showed that there is a relationship between hypertension and the incidence of arterial stiffness, especially in the elderly. Blood pressure management aims to prevent damage to various target organs such as the heart, brain, kidneys, eyes and peripheral arteries. Papaya leaves (Carica papaya L.) have been known empirically to treat hypertension. This study aimed to determine the effect of papaya leaves processed into Nori preparation on blood pressure and arterial stiffness. Methods: This study was carried out on animal models of male Wistar rats induced hypertension. A total of 30 male-Wistar rats were randomly divided into 6 groups consisting of control negative group and control positive group (received drug carriers), the group received captopril $2.5 \mathrm{mg} / \mathrm{kg}$ and groups received Nori of papaya leaves 5,10 and $20 \%$ in their diet. All groups except the control negative group received $66 \%$ fructose in their food for 21 days. Parameters measured were systolic and diastolic blood pressure, pulse wave velocity
\end{abstract}

(PWV) on days 0, 7, 14 and 21 after treatment. Results: The group received Nori $10 \%$ showed normalize both systolic and diastolic blood pressure and a decreased in arterial stiffness compared to the group received captopril ( $p>0.05$ ). Conclusion: It can be concluded that papaya leaves in Nori preparation is effective as an antihypertensive and reduced arterial stiffness. Key words: Arterial stiffness, Blood pressure, Carica papaya L., Hypertension, Pulse wave velocity.

Correspondence

Dr. Patonah Hasimun

Pharmacology Research Group, Faculty of Pharmacy, Bhakti Kencana University, Bandung, West Java, INDONESIA.

Phone: +62 8562201473

Email: patonah@bku.ac.id

DOI: 10.5530/jyp.2020.12.12

\section{INTRODUCTION}

Hypertension, also known as high blood pressure, is defined as a rise in blood pressure $\geq 140 / 90 \mathrm{mmHg} .{ }^{[1]}$ Hypertension is the most common cardiovascular disease and the main cardiovascular risk factors including atherosclerosis, coronary artery disease, heart failure, renal insufficiency, stroke and dissection of aortic aneurysm. Hypertension is a health problem that is common in developing countries including Asia and is a major cause of morbidity and mortality in the world. it was reported that 7 out of every 10 patients did not receive adequate treatment in the Indonesian population. ${ }^{[2]}$

There is a strong relationship between the hardening of the arteries and aging. This can be observed in almost all populations around the world. It is now well known that the aortic pulse wave velocity (PWV), as a measure of arteries distensibility, predicting outcomes in various populations including hypertension. Even reported that aortic PWV is a better predictor of future events than blood pressure. Hardening of the arteries, as a marker of cardiovascular risk factors, also plays an important role in the development of atherosclerotic plaques. Therefore, arterial stiffness can be a target for new therapies to prevent cardiovascular morbidity and mortality. ${ }^{[3]}$

Antihypertensive agents affect arterial stiffness in 2 ways, both indirectly through a decrease in arterial pressure and directly through effects on the components of the arterial wall. Theoretically, effective antihypertensive agents should be able to reduce blood pressure and reduce arterial stiffness. In fact, in patients with end-stage renal failure, there is a greater benefit through antihypertensive therapy that reduces PWV and arterial pressure compared to just a decrease in arterial pressure alone. ${ }^{[4]}$
Epidemiological studies confirm that arterial stiffness is an independent predictor of poor cardiovascular events that contribute significantly to systolic hypertension, diastolic dysfunction, the impaired oxygen supply in the myocardium and progression of kidney disease. Although arterial stiffness is associated with aging, it is also accelerated by the presence of obesity and diabetes mellitus in earlier ages. Increased obesity is in line with increased arterial stiffness and is largely triggered by lifestyle inactivity, as well as high consumption of fructose, sodium and fat. Obesity activates the renin-angiotensin-aldosterone system and increases oxidative stress and inflammation in vascular tissue. ${ }^{[5]}$

Hypertension treatment aims to prevent the occurrence of morbidity and mortality due to increased blood pressure. Increased blood pressure must be managed properly to avoid damage to kidney, brain, heart function. However, current therapies have not been able to reduce the prevalence of hypertension. So the development of drugs for hypertension is still ongoing. One herbal medicine that has the potential to reduce blood pressure is papaya leaf (Carica papaya L.). Papaya leaves have various pharmacological effects but their use is still limited due to the extraordinary bitter taste. In this study, papaya leaves were modified into Nori preparations. Nori is a typical Japanese food that is usually used in making sushi, flat and usually made of seaweed. Nori preparations have the advantage of having an acceptable taste. This study aimed to examine the effectiveness of papaya leaves in Nori preparations as antihypertensive and improvement of arterial elasticity in animal models of hypertension induced with a high fructose diet for 21 days. 


\section{MATERIALS AND METHODS}

\section{Ethical approval}

This study was conducted in the Pharmacology laboratory of Faculty of Pharmacy, Bhakti Kencana University, Bandung, West Java, Indonesia. All procedure in this study was approved by the ethical committee, Padjadjaran University, Sumedang, Indonesia and obtained ethical clearance (no 399/UN6.C.16PN/2017).

\section{Experimental animals}

Male Wistar rat weighing approximately 200-250 g (2-3 months) were obtained from D Wistar provider animal for experimental purpose. All animal were placed in plastic cages with free access to standard commercial food and drinking water. The cages were placed in the room with 12 $\mathrm{hr}$ alternates light and dark cycles.

\section{Nori Preparation of papaya leaves}

The part of Carica papaya L. plant used in this study was papaya leaves obtained from Manoko Lembang plantations, Bandung, Indonesia. Botanical identification was carried out at the Laboratory of Biology, Faculty of Mathematics and Natural Sciences, Padjajaran University, Bandung, Indonesia. (No. 088/HB/02/2017)

Fresh papaya leaves are cleaned from the dirt that is attached under running water. A total of $300 \mathrm{~g}$ of papaya leaves were boiled with the addition of $5 \mathrm{~g}$ of low sodium salt (purchased from local Pharmacy) for $5 \mathrm{~min}$ to reduce the bitter taste of papaya leaves. Furthermore, the decoction of papaya leaves is filtered and squeezed, then mashed using a blender (Miyako blender). Papaya leaves that have been mashed are mixed with 7 g powdered seaweed stew in $900 \mathrm{~mL}$ aquadest (Swallow brand seaweed purchased from the local grocery). The papaya leaves are mixed with seaweed stew, with a ratio of $4: 1$. Then it is ground into thin sheets and dried in an oven at $100^{\circ} \mathrm{C}$ for $30 \mathrm{~min}$. Nori preparation of Carica papaya leaves processed with a variety of concentrations of 5, 10 and $20 \%$ mixed with standard feed containing high-fructose $66 \%$.

\section{High-fructose diet composition}

Diets containing high fructose are made by mixing standard feed for mice (purchased from animal food grocery) mixed with D-Fructose by $66 \%$ until homogeneous. Then milled and dried in an oven at $100^{\circ} \mathrm{C}$ for $30 \mathrm{~min}$

\section{Experimental design}

Thirty male Wistar rats which had been acclimatized for 14 days were then grouped randomly into 6 groups consisting of negative control group (received drug carriers), positive control group (received drug carriers), group received captopril $2.5 \mathrm{mg} / \mathrm{kg}$, the treatment group received Nori dose 5, 10 and 20\%. All groups except the normal group received a high fructose diet 21 days. On the $21^{\text {st }}$ day blood pressure was measured and the pulse wave velocity.

\section{Measurement of blood pressure}

Measurement of systolic and diastolic blood pressure on day 0, 7, 14 and 21 used a non-invasive method "CODA Kent Scientific Corporation" which can read systolic and diastolic blood pressure. The tool uses a Volume Pressure Recording (VPR) sensor type.

\section{Measurement of pulse wave velocity}

PVW measurements are carried out using non-invasive methods. PWV measurements are carried out according to the method reported in previous studies. ${ }^{[6]}$ Measurements of arterial stiffness were carried out on day 21 after treatment. This method was done by measuring the speed of blood flow coming out of the heart to the tail base of the test animal using an electrocardiogram (ECG) and photoplethysmogram (PPG) sensors. An increase in time taken indicates arterial stiffness.

\section{Statistical analysis}

Data obtained analysis by one-way ANOVA post hoc test and presented as mean \pm standard deviation. Furthermore, analysis statistically was performed for comparing among the treatment group with an LSD test using the SPSS program (SPSS V. 17.0). statistically significant was considered as $P$ value $\leq 0.05$.

\section{RESULTS}

The results of an examination of the phytochemical components in fresh papaya leaves are shown in Table 1. Carica papaya L is one of the plants that have various benefits both as food and health care and treatment of various diseases including hypertension. Its pharmacological activity is related to the content of its active compounds including alkaloids, flavonoids, cardiac glycosides, saponins. ${ }^{[7,8]}$

\section{Effect of Carica papaya leaves on systolic blood pressure}

The results of systolic blood pressure measurements on days $0,7,14$ and 21 are shown in Table 2. The group that received a high fructose diet showed an increase in systolic blood pressure by $35 \%$. While the group that received papaya leaves did not show an increase in systolic blood pressure.

\section{Effect of papaya leaves in Nori preparation on diastolic blood pressure}

Diastolic blood pressure measurement results are shown in Table 3. The group that received a high-fructose diet showed an increase in diastolic blood pressure by $11 \%$ on day 21 . While the group receiving Nori did not show an increase in diastolic blood pressure (Table 3 ).

\section{Effect of papaya leaves in Nori preparation on arterial stiffness}

A high-fructose diet causes arterial stiffness which is characterized by an increase in the PWV value (Table 4). Administration of $66 \%$ fructose in the diet for 21 days increased arterial stiffness by $22 \%$. The administration Nori of papaya leaves diet 5, 10 and 20\% can reduced PWV values by 31,39 and $33 \%$ respectively.

\section{DISCUSSION}

The provision of $66 \%$ high-fructose diet for 21 days can increase systolic and diastolic blood pressure significantly different than the normal group (Table 2 and 3). Fructose increases blood pressure through the formation of aldehyde conjugate levels which are the result of fructose metabolism. Aldehyde binds to protein membranes which cause $\mathrm{Ca}^{+}$ channel disturbances which increase free calcium levels, peripheral resistance and increased blood pressure. ${ }^{[9]}$

Table 1: Phytochemical content in papaya leaves (Carica papaya L.).

\begin{tabular}{ccc}
\hline No & Compound & Papaya leaves \\
\hline 1 & Alkaloid & + \\
2 & Flavonoid & + \\
3 & Tannin & + \\
4 & Saponin & + \\
5 & Triterpenoid & + \\
\hline
\end{tabular}

+ : identified 
Table 2: Effect of papaya leaves on systolic blood pressure $(\mathrm{mmHg})$ on day $0,7,14$ and 21 after treatment.

\begin{tabular}{ccccc}
\hline \multirow{2}{*}{$\begin{array}{c}\text { Treatment } \\
\text { group }\end{array}$} & \multicolumn{4}{c}{ Systolic blood pressure (mean \pm SD) on day } \\
\cline { 2 - 5 } & 0 & 7 & 14 & 21 \\
\hline $\begin{array}{c}\text { Negative } \\
\text { control }\end{array}$ & $113.8 \pm 1.09$ & $113.8 \pm 1.09 \alpha$ & $114.2 \pm 0.44 \alpha$ & $114.6 \pm 0.83^{*} \alpha$ \\
$\begin{array}{c}\text { Positive } \\
\text { control }\end{array}$ & $114.2 \pm 0.83$ & $127.6 \pm 1.09^{*}$ & $144.8 \pm 0.83^{*}$ & $174.8 \pm 0.83^{*}$ \\
$\begin{array}{c}\text { Captopril 2.5 } \\
\text { mg/kg }\end{array}$ & $113.6 \pm 0.89$ & $114.6 \pm 0.54 \alpha$ & $113.8 \pm 0.44 \alpha$ & $112 \pm 0.70 \alpha$ \\
$\begin{array}{c}5 \% \text { of papaya } \\
\text { leaves }\end{array}$ & $113.8 \pm 0.83$ & $114.2 \pm 0.83 \alpha$ & $113.4 \pm 0.54 \alpha$ & $110.8 \pm 0.83^{*} \alpha$ \\
$\begin{array}{c}\text { 10 \% of } \\
\text { papaya leaves }\end{array}$ & $114.6 \pm 1.14$ & $114.6 \pm 0.89 \alpha$ & $113.6 \pm 0.89 \alpha$ & $112.8 \pm 0.83 \alpha$ \\
20\% of papaya & $113.6 \pm 0.89$ & $113.8 \pm 0.83 \alpha$ & $111 \pm 1.58 \alpha$ & $110.8 \pm 0.83^{*} \alpha$ \\
leaves & & & & \\
\hline
\end{tabular}

Table 3: Effect of papaya leaves in Nori preparation on diastolic blood pressure $(\mathrm{mmHg})$ on day $0,7,14$ and 21 after treatment.

\begin{tabular}{ccccc}
\hline \multirow{2}{*}{$\begin{array}{c}\text { Treatment } \\
\text { group }\end{array}$} & \multicolumn{5}{c}{ Diastolic blood pressure (mean \pm SD) on day } \\
\cline { 2 - 5 } & 0 & 7 & 14 & 21 \\
\hline $\begin{array}{c}\text { Negative control } \\
\text { Positive control }\end{array}$ & $85.2 \pm 0.83$ & $83.8 \pm 0.83^{*} \alpha$ & $83.8 \pm 0.83^{*} \alpha$ & $84.2 \pm 0.83^{*} \alpha$ \\
$\begin{array}{c}\text { Captopril } 2.5 \\
\text { mg/kg }\end{array}$ & $84.6 \pm 0.54$ & $88.2 \pm 0.83^{*}$ & $90.8 \pm 0.83^{*}$ & $94.8 \pm 0.83^{*}$ \\
$\begin{array}{c}\text { 5\% papaya leaves } \\
\begin{array}{c}10 \% \text { papaya } \\
\text { leaves }\end{array}\end{array}$ & $84.8 \pm 1.30$ & $85.8 \pm 0.83 \alpha$ & $82.4 \pm 1.34 \alpha$ & $82.2 \pm 0.83 \alpha$ \\
$\begin{array}{c}\text { 20\% papaya } \\
\text { leaves }\end{array}$ & $83.8 \pm 0.89$ & $84.2 \pm 0.83 \alpha$ & $83.2 \pm 0.83 \alpha$ & $82.8 \pm 0.83^{*} \alpha$ \\
\hline
\end{tabular}

$\left({ }^{*}\right)$ : There was a significant difference compared to group received captopril 2.5 $\mathrm{mg} / \mathrm{kg}(p<0.05)$

(a): There was a significant difference compared to the positive control group $(p<0.05)$

Nori of papaya leaves in 5, 10 and 20\% diet can reduce systolic blood pressure by 37,36 and $37 \%$ respectively (Table 2 ). In addition, reducing diastolic blood pressure by 13, 13 and 14\% respectively (Table 3 ). The results of this study are in line with previous studies which reported that papaya leaves can reduce glucose and cholesterol levels in the blood. ${ }^{[10]}$ It is known that diabetes mellitus is often accompanied by hyperlipidemia and hypertension. Uncontrolled diabetes mellitus increases the risk of complications of kidney damage which results in an increase in blood pressure (hypertension). In addition, insulin also plays a role in regulating lipoprotein synthesis. The presence of insulin resistance in diabetes causes overproduction of lipoproteins in the liver resulting in hyperlipidemic. ${ }^{[11]}$ Papaya leaves have been used by Indonesian people as a healthy vegetable, dealing with various diseases including high blood pressure. Moreover, research on phytochemical components and pharmacological activities have been widely reported. Therefore, papaya leaves can be considered a functional food for maintaining health. One of its potential as an antioxidant that plays a role in counteracting free radicals as an initial stage of the disruption in the body system.

Pulse Wave Velocity (PWV) is an important index to determine the risk of cardiovascular dysfunction and is used as an early warning for possible risk factors. The PWV measurement method we use is a non-invasive
Table 4: Effect of Carica papaya leaves in Nori preparation on pulse wave velocity (PWV) for a 21-day treatment.

\begin{tabular}{cc}
\hline Treatment group & PWV on T21 \\
\cline { 2 - 2 } & Mean \pm SD $(\mathbf{c m} / \mathbf{s})$ \\
\hline Negative control & $437.60 \pm 19.05 \alpha$ \\
Positive control & $563.30 \pm 14.03^{*}$ \\
Captopril $2.5 \mathrm{mg} / \mathrm{kg}$ & $300.23 \pm 16.71 \alpha$ \\
5\% papaya leaves & $388.03 \pm 18.14^{*} \alpha$ \\
10\% papaya leaves & $343.03 \pm 19.99 \alpha$ \\
20\% papaya leaves & $375.94 \pm 22.99^{*} \alpha$ \\
\hline
\end{tabular}

$\left.{ }^{*}\right)$ : There was a significant difference compared to group received captopril 2.5 $\mathrm{mg} / \mathrm{kg}(p<0.05)$

(a): There was a significant difference compared to the positive control group $(p<0.05)$

method, of course, this is an easy method to determine arterial stiffness accurately, without the need for test animal surgery. Based on the PWV values obtained, it becomes an illustration of how hard the heart works and can also be a reference for determining the diagnosis of arterial stiffness.

In general, PWV measurements are performed using two blood vessel measurement points, which are defined as the ratio of the pulse wave transmission distance and the pulse transmission time. Therefore, for the design of PWV measurement devices, a sensor is needed to measure the condition of the arteries to obtain the time acquisition signal and get a time difference from the pulse wave signal. The high value of PWV (Pulse Wave Velocity) shows the presence of higher arterial stiffness. The stiffness of the arteries causes the inflexibility of the arterial wall to increase because the energy from the pulse of each blood pressure cannot be stored in the flexible blood vessel wall.

The papaya leaf diet as a Nori preparation can reduce arterial stiffness as evidenced by a reduction in PWV rates compared to the control group (Table 4). These results support previous studies reported that Carica papaya can inhibit the occurrence of oxidative stress through the inhibition of Inducible Nitric Oxide Synthase (iNOS) activity ${ }^{[12]}$ which inhibits the occurrence of inflammation. ${ }^{[13]}$ Papaya leaves have been reported to have high saponin and polyphenol compounds and have been empirically used to treat various diseases. In addition, papaya leaf ethanol extract has been reported to produce a high antioxidant activity. ${ }^{[14]}$

It has been reported that aging of the heart organ physiologically decreases the tolerance of the heart to oxidative stress thereby increasing the risk of cardiovascular disease. ${ }^{[15]}$ This occurs due to damage to blood vessel endothelial cells characterized by increased arterial stiffness. The results of this study indicate that one mechanism of action of papaya leaves in lowering blood pressure includes reducing arterial stiffness (Table 4)

\section{CONCLUSION}

All together can be concluded that supplementation papaya leaves in Nori preparation had an effect in stabilizing systolic and diastolic blood pressure and reduced arterial stiffness in animal model hypertension.

\section{ACKNOWLEDGEMENT}

Authors thank to LPPM, Bhakti Kencana University, Bandung for funding the research. 


\section{CONFLICT OF INTEREST}

The authors declare none.

\section{ABBREVIATIONS}

ECG: Electrocardiogram; PWV: Pulse wave velocity; VPR: Volume Pressure Recording.

\section{REFERENCES}

1. Dennison-Himmelfarb C, Handler J, Lackland DT, LeFevre ML, MacKenzie TD, Ogedegbe O, et al. Evidence-Based Guideline for the Management of High Blood Pressure in Adults Report From the Panel Members Appointed to the Eighth Joint National Committee (JNC 8). JAMA. 2014;311(5):507-20.

2. Widjaja FF, Santoso LA, Barus NRV, Pradana GA, Estetika C. Prehypertension and hypertension among young Indonesian adults at a primary health care in a rural area. Med J Indones. 2013;22(1):39-45.

3. Sun Z. Aging, arterial stiffness and hypertension. Hypertension. 2015;65(2):252 6.

4. Wilkinson IB, Franklin SS, Cockcroft JR. Nitric oxide and the regulation of large artery stiffness: From physiology to pharmacology. Hypertension. 2004;44(2):112-6.

5. Aroor A, DeMarco V, Jia G, Sun Z, Nistala R, Meininger G, et al. The Role of Tissue Renin-Angiotensin-Aldosterone System in the Development of Endothelial Dysfunction and Arterial Stiffness. Frontiers in Endocrinology. 2013;4:161. Available from: https://www.frontiersin.org/article/10.3389/fendo.2013.00161

6. Zakaria $\mathrm{H}$, Hasimun P. Non-invasive pulse wave velocity measurement in mice.
In: 2017 International Seminar on Sensors, Instrumentation, Measurement and Metrology. 2017;95-8.

7. Rahmani AH, Aldebasi YH. Potential role of Carica papaya and their active constituents in the prevention and treatment of diseases. Int J Pharm Pharm Sci. 2016;8(1):11-5.

8. Yogiraj V, Goyal PK, Chauhan CS, Goyal A, Vyas B. Carica papaya Linn: an overview. Int J Herb Med. 2014;2(5):1-8.

9. Vasdev S, Longerich L, Gill V. Prevention of fructose-induced hypertension by dietary vitamins. Clin Biochem. 2004;37(1):1-9.

10. Maniyar $Y$, Bhixavatimath P. Antihyperglycemic and hypolipidemic activities of aqueous extract of Carica papaya Linn. leaves in alloxan-induced diabetic rats. $J$ Ayurveda Integr Med. 2012;3(2):70.

11. Adeli K, Taher J, Farr S, Xiao C, Lewis GF. Diabetic dyslipidaemia. In: Biochemistry of Lipids, Lipoproteins and Membranes (Sixth Edition). Elsevier. 2015;54973.

12. Ojo OA, Ojo AB, Osukoya OA, Ajiboye BO. Aqueous Extract of Carica papaya Linn Roots Halts Sodium Arsenite-Induced Renal Inflammation through Inhibiting Adenosine Deaminase, 8-Hydroxy-2'-Deoxyguanosine, C-Reactive Protein and Inducible Nitric Oxide Synthase Activity. Serbian J Exp Clin Res. 2017;18(4):323-30.

13. Rahman IU, Bashir M, Rahman KU. Evidence of the nephroprotective effect of Carica papaya $L$. leaves in streptozotocin-induced diabetic rats. IJTK. 2016;15(3):460-5

14. Vuong QV, Hirun S, Chuen TLK, Goldsmith CD, Murchie S, Bowyer MC, et al. Antioxidant and anticancer capacity of saponin-enriched Carica papaya leaf extracts. Int J Food Sci Technol. 2015;50(1):169-77.

15. Abete P, Napoli C, Santoro G, Ferrara N, Tritto I, Chiariello M, et al. Agerelated decrease in cardiac tolerance to oxidative stress. J Mol Cell Cardiol. 1999;31(1):227-36.

Article History: Submission Date :15-09-2019 ; Revised Date : 01-12-2019 ; Acceptance Date : 17-12-2019

Cite this article: Hasimun P, Sulaeman A, Maharani IDP. Supplementation of Carica papaya Leaves (Carica papaya L.) in Nori preparation Reduced Blood Pressure and Arterial Stiffness on Hypertensive Animal Model. J Young Pharm. 2020;12(1):63-6. 